\title{
Clinical and Laboratory Parameters Predicting Severity of Dengue Infection
}

\author{
Durgesh Gopalrao Deshmukh ${ }^{1}$, Vivek Madhukarrao Gujar ${ }^{1 *}$, \\ Supriya Sanjay Tankhiwale ${ }^{1}$, Pragati Abhimanyu Bulle ${ }^{1}$ and Vijay Kishanrao Domple ${ }^{2}$ \\ ${ }^{1}$ Department of Microbiology, Shri Vasantrao Naik Government Medical College \\ Yavatmal, Maharashtra, India \\ ${ }^{2}$ Department of Community Medicine, Shri Vasantrao Naik Government Medical College \\ Yavatmal, Maharashtra, India \\ *Corresponding author
}

\begin{tabular}{|c|c|}
\hline & A B S T R A C T \\
\hline & \multirow{5}{*}{$\begin{array}{l}\text { Dengue infections are currently one of the most rapidly emerging arboviral infections in } \\
\text { the world. There is high mortality associated with severe dengue infection so we } \\
\text { conducted study to predict various factors indicating severity of dengue infection. This } \\
\text { cross- sectional study conducted in tertiary care hospital of central India. Data associated } \\
\text { with various clinical features of dengue infection collected in predesigned questionnaire. } \\
\text { Patient tested for complete blood count, serum alanine transaminase (ALT), aspartate } \\
\text { transaminase (AST) levels, early dengue NS1 capture ELISA (Panbio, Brisbane, Australia) } \\
\text { and commercial capture-IgM and IgG ELISA (Panbio, Brisbane, Australia). Total } 678 \\
\text { suspected patients for dengue infection included in the study, 128(18.9\%) patients were } \\
\text { diagnosed as dengue positive, 58(45.3\%) patients showed severe dengue infection, } \\
66(51.6 \%) \text { patients had thrombocytopenia, } 38(29.7 \%) \text { had raised liver enzymes, } 62 \text { ( } 48.4 \%) \\
\text { patients had decreased total leukocyte counts. Our study demonstrated various clinical and } \\
\text { laboratory parameters to predict severity of the dengue infection which can be used to } \\
\text { categorize the patients in resource poor country like India for the management of dengue } \\
\text { infection. }\end{array}$} \\
\hline & \\
\hline $\begin{array}{l}\text { Sever dengue } \\
\text { infection, Clinical } \\
\text { and laboratory } \\
\text { parameters, NS1 } \\
\text { capture ELISA }\end{array}$ & \\
\hline Article Info & \\
\hline $\begin{array}{l}\text { Accepted: } \\
\text { 18 May } 2019 \\
\text { Available Online: } \\
\text { 10 June } 2019\end{array}$ & \\
\hline
\end{tabular}

\section{Introduction}

Dengue infections are currently one of the most rapidly emerging arboviral infections in the world, ${ }^{1}$ which result in 390 million infections every year. ${ }^{2}$ It causes significant morbidity and mortality in developing nations. ${ }^{3}$ There are different spectrum of dengue infections like asymptomatic, simple undifferentiated viral fever to clinical complications like dengue hemorrhagic fever (DHF) and dengue shock syndrome (DSS). ${ }^{4}$ As there is no effective antiviral treatment or a licensed vaccine to prevent infection, early case detection of complicated dengue infection and its meticulous fluid management and monitoring for complications is currently the only option available. Earlier case fatalities due to dengue infection have been reported to be around $2.5 \%$ to $5.4 \% .{ }^{5,6}$ Shock 
and organ impairment have been shown to be the most important factors that lead to fatalities in dengue infection. ${ }^{7,8}$ Early interventions in sever dengue infection significantly decreases the case fatality rate. ${ }^{9}$ There are different clinical and laboratory parameters which can help in early detection of sever dengue. So the current study is planned to predict various factors indicating severity of dengue infection.

\section{Materials and Methods}

The cross-sectional study was carried out from the month of $1^{\text {st }}$ June 18 to $30^{\text {th }}$ November 2018 at department of Microbiology the Shri Vasantrao Naik Govt Medical College Yavatmal, which is a teaching tertiary care hospital in Yavatmal, Maharashtra India, with the bed strength of over 780. All patients, who were admitted with suspected acute dengue infection, were recruited after obtaining informed written consent. The study was approved by the Institutional Ethics Committee. Patients who had a febrile illness due to other infections were excluded. All clinical features such as fever, low blood pressure, presence of any bleeding manifestations and presence of any possible fluid accumulation in the pleural cavity and abdomen were mentioned in predesigned questionnaire for each patients. Presence of petechiae, ecchymoses, epistaxis, haematemesis, melaena noted (bleeding manifestations). Recordings of laboratory investigations such as complete blood counts, Serum alanine transaminase (ALT) and aspartate transaminase (AST) levels done. ${ }^{10}$ Based on the 2011 WHO diagnostic criteria, shock was defined as lowering of pulse pressure to $20 \mathrm{mmHg}$ or less or the presence of signs of poor capillary perfusion (cold extremities, poor capillary refill or a rapid pulse rate). ${ }^{3}$ Suspected dengue infection was confirmed by testing the serum samples which were collected on the day of admission with the early dengue NS1 capture ELISA (Panbio, Brisbane, Australia) and commercial capture-IgM and IgG ELISA (Panbio, Brisbane, Australia). Positive and negative controls were included as a part of the assessment. In order to determine the usefulness of the NS1 antigen positivity as a marker of severe disease, we classified into severe dengue infection and non-severe dengue infection, if the patients had bleeding manifestations or other clinical complications and any one of the following laboratory features such as platelet count of $<1,50,000$ cells $/ \mathrm{mm}^{3}$ or liver enzyme levels of $>40 \mathrm{IU}$ considered as severe dengue infection. Those who did not have even one of the above criteria were categorized to the non-severe dengue infection. Data was entered and tabulated in Microsoft excel sheet and analyzed by statistical software EpiInfo ${ }^{\mathrm{TM}}$ Version 7 (Atlanta, Georgia, USA) for frequencies, percentages and scatter diagram.

\section{Results and Discussion}

Thus total 678 suspected dengue patients referred for laboratory diagnosis. Of 678 , total $128(18.9 \%)$ patients were diagnosed as dengue positive by dengue NS1 pan bio ELISA, dengue IgM pan bio ELISA, dengue IgG pan bio ELISA. Of 128 positive patients, $72(56.2 \%)$ were males and $56(43.8 \%)$ were females. About the age distribution of 128 positive patients, $45(35.2 \%)$ patients were in the age group of 1 to 12 years, $71(55.5 \%)$ patients were in the age group of 13 to 48 years and $12(9 \%)$ patients were in the age group of 49 to 72 years. Regarding the history of fever among dengue positive patients, 80 $(62.5 \%)$ patients had the history of 1 to 5 days of fever, $48(37.6 \%)$ patients had the history of 6 to 8 days of fever. In view of severity of dengue infection, $58(45.3 \%)$ patients showed dengue infection. Of 58 (45.3\%), severe dengue infection, hypotension $27(21.1 \%)$, petechiae rash 12(7.6\%), meningitis 
4(3.12\%), ascitis $2(1.6 \%)$, maleana $1(0.8 \%)$ encephalitis $2(1.6 \%)$, pulmonary haemorrhage $1(0.8 \%)$ were the clinical complication observed in the patients (Table 1).

Of 128 positive dengue infection, 29 (22.7\%) patients only NS1 pan bio ELISA positive, 74 (57.8\%) only IgM positive, 15 (11.7\%) patients both NS1 and IgM Elisa positive, $8(6.25 \%)$ patients both IgM positive and IgG positive, $2(1.6 \%)$ patients all NS1, IgM and $\mathrm{IgG}$ positive.

With respective to platelet count, total WBC count, ALT and AST in 128 positive dengue infection, $66(51.6 \%)$ patients had platelets count $<1,50,000$ and $62(48.4 \%)$ patients had platelets count $>1,50,000$. The $61(47.7 \%)$ patients had total WBC count less than 5,000, $52(40.6 \%)$ patients were in the range of 5,000 to 10,000 and $15(11.7 \%)$ patients had > 10,000 . The $38(29.7 \%)$ patients had ALT in the range of $1-40 \mathrm{IU} / \mathrm{ml}$ and $90(70.3 \%)$ patients were $>41 \mathrm{IU} / \mathrm{ml}$. The $34(26.6 \%)$ patients had AST in the range of 1-40 IU/ml and $94(73.4 \%)$ patients were $>41 \mathrm{IU} / \mathrm{ml}$. The
$39(30.5 \%)$ patients had severe dengue infection and thrombocytopenia, 16(12.5\%) patients had severe dengue infection and normal platelet count, 13(10.6\%) patients had non-severe dengue infection with thrombocytopenia and 60 (46.9\%) patients had non-severe dengue infection with normal platelets (Table 2).

Of 46 NS1 ELISA positive patients, 44 (91.3\%) had panbiounites $>20$, and 4 (8.7\%) patients had panbiounits in range of 11-20 panbiounits.

We applied the chi-square test to test association between NS1 positivity in patients and severe dengue infection, NS1 positivity in patients and raised liver enzymes. We observed significant association between NS1 positivity in patients and severe dengue infection $(\mathrm{P}<0.001)$ and also with raised liver enzymes $(\mathrm{P}<0.001)$

We found inverse correlation between NS1 Panbio Unit and level of platelet count (Figure 1) and also with total WBC count.

Table.1 Showing dengue complications

\begin{tabular}{|l|l|}
\hline Dengue complication & No. patients \\
\hline Petechiae rash & $12(7.6 \%)$ \\
\hline Hypotension & $27(21.1 \%)$ \\
\hline Pleural effusion & $9(7.03 \%)$ \\
\hline Meningitis & $4(3.12 \%)$ \\
\hline Ascitis & $2(1.6 \%)$ \\
\hline Maleana & $1(0.8 \%)$ \\
\hline Encephalitis & $2(1.6 \%)$ \\
\hline Pulmonary haemorrhage & $1(0.8 \%)$ \\
\hline Total & $58(45.31 \%)$ \\
\hline
\end{tabular}


Table.2 Association between complicated dengue infection and thrombocytopenia

\begin{tabular}{|l|l|}
\hline $\begin{array}{l}\text { Patients with severe dengue infection and } \\
\text { thrombocytopenia }\end{array}$ & $39(30.5 \%)$ \\
\hline $\begin{array}{l}\text { Patients with severe dengue infection and } \\
\text { normal platelets }\end{array}$ & $16(12.5 \%)$ \\
\hline $\begin{array}{l}\text { Clinically non-severe dengue patients with } \\
\text { thrombocytopenia }\end{array}$ & $13(10.6 \%)$ \\
\hline $\begin{array}{l}\text { Clinically non-severe dengue patients with } \\
\text { normal platelets }\end{array}$ & $60(46.9 \%)$ \\
\hline
\end{tabular}

Fig.1 Association between NS1 positivity and thrombocytopenia

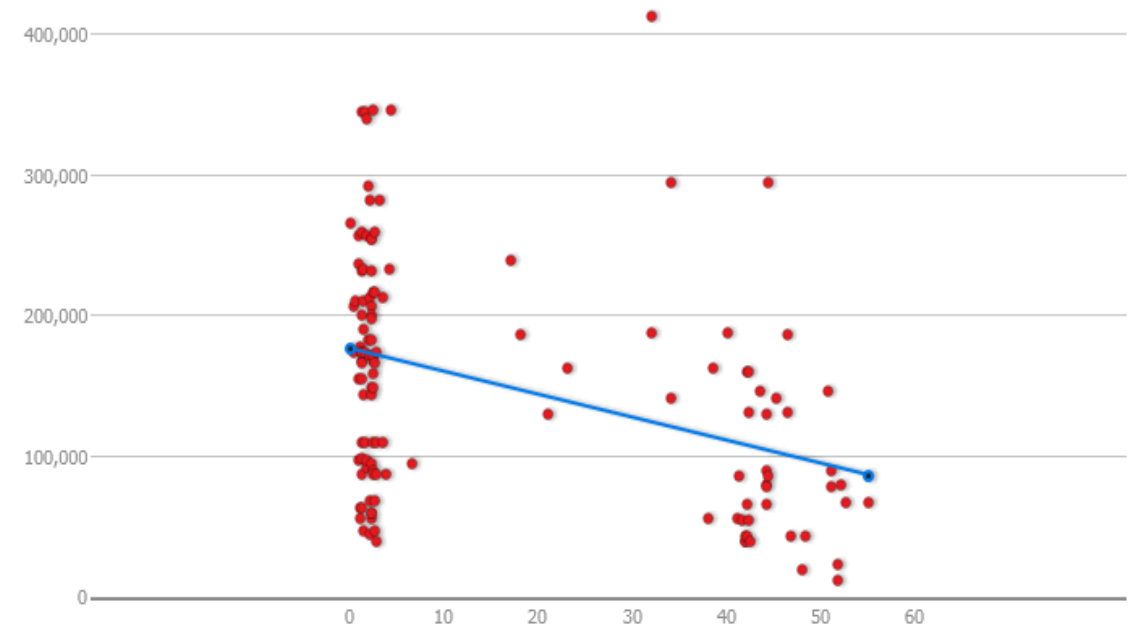

Dengue is an important infection affecting many lives in India. In our region, maximum numbers of patients we get followed by the rainy season as there is increase in the growth of mosquitoes. In these periods, extrinsic incubation period of dengue is short ${ }^{11}$.

In our study, all age groups and both sexes were equally affected by dengue infection. Fever is the predominate symptom of dengue infection. Maximum number of patients had history of fever from 1-5days. Paranavitane A ${ }^{10}$ et al., study also demonstrated the similar findings in their study.
In our study, hypotension and petechial rashes were predominant clinical complications and other clinical complications were pleural effusion, meningitis, ascitis, maleana, encephalitis, pulmonary haemorrhage. Paranavitane et al., ${ }^{10}$ demonstrated similar complications in dengue patients. In the present study, thrombocytopenia, total WBC count and raised liver enzymes were important laboratory parameters to predict severity of dengue infection.

In the current study, there was positive correlation between NS1 positivity in patients 
and clinical features of severe dengue infection like thromobocytopenia and total WBC count. We had evaluated NS1 antigen positivity in terms of its panbiounits parameter to predict the severity of dengue infections as it indicates viremia in the dengue patients. Hence the qualitative reporting like 'NS1 positive' or 'NS1 Negative' is not enough. It should be reported in the terms of panbiounits because the raised levels of panbiounts predict the severity of dengue infection.

Many studies reported the usefulness of liver transaminase levels, platelet counts, other clinical and laboratory parameters to predict severity of dengue infection and also suggested that none of these parameters can be used alone to predict severe dengue infection. ${ }^{12-16 .}$ We also found that positive correlation between liver transaminase levels with NS1 panbiounits and inverse correlation of NS1 panbiounts with total WBC count. Libraty et al., ${ }^{17}$ had showed that NS1 levels were higher in patients with DHF throughout the illness.

The present study demonstrated that history of 1-5 days of fever, bleeding manifestations, NS1 antigen positivity, increased NS1 panbiounits >20 units, thrombocytopenia, raised liver enzymes and decreased total WBC counts were clinical and laboratory parameters to predict severity of the dengue infection which can be used to categorize the patients in resource poor country like India for the management of dengue infections.

\section{References}

Bhatt S, Gething PW, Brady OJ, Messina JP, Farlow AW, Moyes CL, Drake JM, Brownstein JS, Hoen AG, Sankoh O, Myers MF, George DB, Jaenisch T, Wint GR, Simmons CP, Scott TW, Farrar JJ, Hay SI: The global distribution and burden of dengue. Nature 2013, 496(7446): 504-507.

Callaway E: Dengue fever climbs the social ladder. Nature 2007, 448:734-735.

Cavalcanti LP, Coelho IC, Vilar DC, Holanda SG, Escossia KN, Souza-Santos $\mathrm{R}$ :Clinical and epidemiological characterization of dengue hemorrhagic fever cases in northeastern, Brazil. Rev Soc Bras Med Trop 2010, 43(4):355358.

Diaz-Quijano FA, Villar-Centeno LA, Martinez-Vega RA: Predictors of spontaneous bleeding in patients with acute febrile syndrome from a dengue endemic area. J Clin Virol 2010, 49(1):11-15.

Lee LK, Gan VC, Lee VJ, Tan AS, Leo YS, Lye DC: Clinical relevance and discriminatory value of elevated liver aminotransferase levels for dengue severity. PLoS Negl Trop Dis 2012, 6(6):e1676.

Leo YS, Thein TL, Fisher DA, Low JG, Oh HM, Narayanan RL, Gan VC, Lee VJ, Lye DC: Confirmed adult dengue deaths in Singapore: 5-year multi-center retrospective study. BMC Infect Dis 2011, 11:123.

Libraty DH, Young PR, Pickering D, Endy TP, Kalayanarooj S, Green S, Vaughn DW, Nisalak A, Ennis FA, Rothman AL: High circulating levels of the dengue virus nonstructural protein NS1 early in dengue illness correlate with the development of dengue hemorrhagic fever. J Infect Dis 2002, 186(8):11651168.

Macedo GA, Gonin ML, Pone SM, Cruz OG, Nobre FF, Brasil P: Sensitivity and specificity of the world health organization dengue classification schemes for severe dengue assessment in children in rio de janeiro. PLoS One 2014, 9(4):e96314.

Magpusao NS, Monteclar A, Deen JL: Slow 
improvement of clinically- diagnosed dengue haemorrhagic fever case fatality rates. Trop Doct 2003, 33(3):156-159.

Malavige GN, Huang LC, Salimi M, Gomes L, Jayaratne SD, Ogg GS: Cellular and cytokine correlates of severe dengue infection. PLoS One 20127(11):e50387.

Malavige GN, Ogg GS: T cell responses in dengue viral infections. J Clin Virol 2013, 58(4):605-611.

Mutheneni SR, Morse AP, Caminade C et al., Dengue burden in India: Recent trends and importance of climatic parameters. Emerging Microbes and infections. (2017) 512

Ong A, Sandar M, Chen MI, Sin LY: Fatal dengue hemorrhagic fever in adults during a dengue epidemic in Singapore. Int J Infect Dis 2007, 11(3):263-267.
Paranavitane A, Gomes L, Kamaladasa A et $a l$., Dengue NS1 antigen as a marker of sever clinical disease, BMC infectous Disease 2014 14:570

Srikiatkhachorn A, Green S: Markers of dengue disease severity. Curr Top Microbiol Immunol 2010, 338:67-82.

Thomas L, Brouste Y, Najioullah F, Hochedez P, Hatchuel Y, Moravie V, Kaidomar S, Besnier F, Abel S, Rosine J, Quenel P, Cesaire R, Cabie A: Predictors of severe manifestations in a cohort of adult dengue patients. J Clin Virol 2010, 48(2):96-99.

WHO: Comprehensive guidelines for prevention and control of dengue fever and dengue haemorrhagic fever. In Geneva, Switzerland: World Health Organization; 2011.

\section{How to cite this article:}

Durgesh Gopalrao Deshmukh, Vivek Madhukarrao Gujar, Supriya Sanjay Tankhiwale, Pragati Abhimanyu Bulle and Vijay Kishanrao Domple. 2019. Clinical and Laboratory Parameters Predicting Severity of Dengue Infection. Int.J.Curr.Microbiol.App.Sci. 8(06): 2477-2482. doi: https://doi.org/10.20546/ijcmas.2019.806.296 